on its advisory committee. "We do want the input of the pharmaceutical industry, and hope to encourage their participation in offering to share advice and clinical samples," says the head of the NIGMS initiative, pharmacologist Rochelle Long.

However, the NIH is a late starter in the field compared with some companies. Glaxo Wellcome $(\mathrm{GW})$, for example, spends over $£ 30$ million ( $\$ 47$ million) each year on genetics and pharmacogenetics research. "We have been collecting samples from drug trial responders and non-responders and using pharmacogenetics to predict drug efficacy and adverse events for over three years," Alan Roses, the director of genetics at GW told Nature Medicine. By the end of 1999 , GW had done genetic research on samples taken from around 60 clinical trials of 16 compounds in 26 countries, with more than 8,000 samples collected from almost 1,800 clinical sites.

Despite the fact that GW's research on the genetics of patient responses to asthma drugs targeting leukotriene activity overlaps with asthma research funded by the NIH initiative, the company has not received an invitation to work with the NIH. "We might be interested in collaborating with the network researchers, but so far, we haven't been asked," says Roses.

Kristine Novak, New York

\title{
NIH revamps HIV vaccine trials unit
}

In what seems to be an ongoing restructurization of its AIDS research efforts in the face of mounting pressure to come up with effective agent to prevent HIV transmission, the National Institutes of Health $(\mathrm{NIH})$ is to base its center for clinical trials of potential AIDS vaccines in Seattle at the University of Washington.

The new HIV Vaccine Trials Network (VTN) will be directed by AIDS and herpes virologist Larry Corey, and will be based at the Fred Hutchinson Cancer Research Center, with a first-year budget of $\$ 13$ million. About ten "core sites," whose locations are to be announced imminently, will constitute the network.

The VTN merges the AIDS Vaccine Evaluation Group, which handled Phase I and II trials, with some of the functions of the old HIVNET group. HIVNET was established to administer Phase III trials of microbicides, behavioral intervention strategies and potential vaccines, but under the new system, a separate network called the Prevention Trials Network (PTN) is being set up to evaluate the microbicides and interventional efforts.

The PTN director is Ward Cates, of Family Health International, a not-for-profit health contractor, and this network will be headquartered in Research Triangle, North Carolina. Unit sites will be announced by 1 June.

VTN's command structure shifts control away from the NIH hierarchy at Bethesda. Norman Letvin, head of the Viral Pathogenesis Laboratory at Harvard's Beth Israel Hospital and a member of NIH's AIDS Vaccine Research Committee, observes that "NIH and investigators recognized that the tensions inherent in an organization with shared administrative responsibilities was not going to be the best way to get the job done," and adds, "previously, decision-making was blurred, but with this reorganization the responsibility and credit rests squarely in the hands of the academic investigators at the core sites." Research programs will also be initiated and driven more by investigators than by administrators, as in the past.

Corey predicts that the "composition of the network will be very different two or three years from now as it expands into clinical trials sites worldwide." The international focus is important because the greatest need for HIV vaccines lies outside the US. VTN will expand on clade development, as almost all vaccines so far have been developed for clade $B$, the virus that circulates in US and Europe. "We structured the VTN to draw in new researchers and development groups, and to provide them with guidance with things like how to make a GMP lot, and help in getting their products into Phase I development," says Corey.

The creation of the VTN brings a new set of risks, however. Sam Avrett, who is associated with the New York-based Treatment Action Group, says that although VTN brings together all three trial phases, it may be detrimental to break off the vaccine and behavioral intervention branches. "The mucosal biology folks ought to stay in contact with the vaccine folks," he worries. Bill Snow, a community representative who sits on the VTN's scientific steering committee, shares these concerns but also points out that putting everything together would have made the new organization as unwieldy as the old.

Potter Wickware, San Francisco

\section{Japanese research center changes career structure}

Last month, one of Japan's leading biomedical research centers took a step towards the elimination of tenured faculty positions in favor of fixed-term contracts in an effort to create a more favorable working environment for young and foreign scientists. The possibility for universities to shift towards fixed-term employment was opened up by the Education Ministry several years ago. Some scientists and unions have resisted the change and only few universities have taken up the proposal.

The changes at the Institute of Medical Science (IMS) at the University of Tokyo are part of a movement away from the koza system, which provides professors in Japanese universities with a high level of control over junior faculty members. In the long term, all IMS faculty members, including full professors, will be placed on fixed-term contracts and a number of new positions for independent assistant professors will be created. Moreover, junior faculty members will be asked to resign when their supervising professor leaves or retires, rather than being allowed to stay on at the institute, as has been the practice in the past.

The chance of scientists in their $30 \mathrm{~s}$ obtaining full professorships is rare, thus one problem that still needs to be addressed is how to deal with associate professors, or joshu, who do most of the laboratory bench work but have little chance of receiving independent funding and cannot supervise students formally. "The way that highly productive joshu are treated in Japanese universities is an enormous waste of talent," admits IMS director, Ken-ichi Arai.

The difficult joshu position-in terms of workload, pay levels and rigid career trajectory-adds to an unofficial Education Ministry policy of hiring only limited numbers of foreign faculty for national universities, meaning that foreign scientists are offered little incentive to take up an academic position in Japan. But, unlike its support for shortterm contracts, the ministry has so far shown no interest in actively recruiting foreign scientists.

Robert Triendl, Tokyo 